\title{
USF HоRIZONTES
}

APRESENTAÇÃO DA SEÇÃO TEMÁTICA

José Jackson Reis dos Santos ${ }^{1}$

Francisco Mirtiel Frankson Moura Castro²

Osmar Hélio Araújo³

Os artigos apresentados neste número são uma continuidade das discussões publicadas na Revista Horizontes, n.38, v.1, 2020, com o título Docência(s) na educação de pessoas jovens, adultas e idosas: desafios políticos, teóricos e metodológicos para a (trans)formação e resistência(s) no contexto contemporâneo. Os textos desta segunda seção representam perspectivas diversas sobre formação, docência e práticas na educação de pessoas jovens, adultas e idosas. Dentre as temáticas abordadas, os artigos discutem formação, prática docente, livro didático, narrativas de vida, estudo sobre o campo da Matemática, tendo como referência vozes de diferentes pesquisadores. Há uma diversidade de pensamento, direcionada, sobretudo, para uma educação para a indignação, emancipação, democracia e transformação social.

Na escrita dos artigos, há uso de siglas diversas (Educação de Jovens e Adultos - EJA; Educação de Pessoas Jovens e Adultas - EPJA; Educação de Pessoas Jovens, Adultas e Idosas EPJAI). No dossiê, foram mantidas as escolhas dos autores, considerando, sobretudo, o respeito ao pluralismo de ideias e a diversidade de pensamento (epistemológico, teórico, metodológico, político, educacional etc.). Em alguns aspectos, a pluralidade e a diversidade de pensamentos representam avanços do ponto de vista das reflexões para a área. As escolhas dos autores representam, também, diversidades epistemológicas nas análises dos dados. $\mathrm{O}$ mais importante, do nosso ponto de vista, é a defesa de uma educação, também como modalidade da educação básica, mas não só, que priorize a justiça social, a emancipação humana, a democracia, os direitos humanos.

\footnotetext{
${ }^{1}$ Universidade Estadual do Sudoeste da Bahia (UESB), Vitória da Conquista, jackson.santos@uesb.edu.br.

${ }^{2}$ Universidade Estadual do Ceará (UECE), Campi Fortaleza e Itapipoca, mirtielfrankson@gmail.com.

${ }^{3}$ Universidade Federal da Paraíba (UFPB), Campus João Pessoa, osmarhelio@hotmail.com.
} 


\section{HSE HORIZON TES}

O artigo Procesos formativos y práctica docente en educación de jóvenes y adultos, de Gladys Blazich e Maria del Carmen Lorenzatti, escrito em espanhol e oriundo do contexto argentino, socializa resultados de pesquisa desenvolvida no contexto da prática docente de uma professora de jovens e adultos em Chaco, Argentina. A ênfase do texto encontra-se na relação processos formativos e prática docente, discutindo o contexto político da EPJA e da formação docente na Argentina, buscando evidenciar as relações entre prática e processos formativos situados. Diversos saberes são evidenciados no âmbito da prática docente da professora, tanto aqueles voltados ao campo da gestão escolar quanto ao campo pedagógico. O estudo denota a importância da apropriação de conhecimentos administrativos e pedagógicos e explicita preocupação com a inexistência de formação específica para atuação na área. Os resultados expressam um princípio fundamental no campo da formação docente, qual seja: relação indissociável entre prática e formação, face aos desafios cotidianos demandados pelos sujeitos e contextos.

Cibele Barbosa de Araújo Santana e Marco Antonio Leandro Barzano, autores do texto Desafios para a formação docente de jovens e adultos: um olhar para o ensino de ciências e biologia, apresentam resultados de pesquisa, focalizando, especialmente, vivências desenvolvidas no contexto da educação básica em processos de ensino-aprendizagem de Ciências e Biologia, evidenciando desafios pedagógicos enfrentados por licenciandos e recémegressos do curso de Ciências Biológicas. Discutem, num primeiro momento, a experiência de um docente de Ciências e Biologia, numa escola rural do Estado do Rio de Janeiro para, num segundo momento, refletirem sobre uma pesquisa no âmbito do Projovem Urbano e suas especificidades. Explicitam, ainda, diversos desafios da prática docente para lidar, cotidianamente, com jovens e adultos e seus processos de apropriação do conhecimento escolar em Ciências e Biologia. As discussões sobre currículo, prática docente e formação são marcas presentes no artigo, articuladas à defesa pela garantia e efetivação do direito à educação para os sujeitos desta modalidade.

Intitulado Docência na educação de mulheres jovens, adultas e idosas no cárcere, o artigo, cuja autoria é de Ivanilde Apoluceno de Oliveira e Suzianne Silva de Oliveira, aborda a 


\section{HSE H O R I Z O T ES}

educação no cárcere, enfatizando a docência e as questões feministas com mulheres jovens, adultas e idosas, cujo espaço de pesquisa foi um Centro de Reedução Feminina, da cidade de Belém, Estado do Pará. O desenvolvimento de um processo de conscientização crítica e de denúncia de situações de opressão, vividas em diferentes contextos por estas mulheres, é fundamental como ação docente no cárcere, ratificam as autoras. $\mathrm{O}$ artigo reflete sobre docência no cárcere feminino, concepção e prática pedagógica, bem como cultura prisional masculina no cárcere feminino, reafirmando a relevância da escola (e da educação) como direito humano neste espaço social e educacional. Problematizam-se, no texto, a invisibilidade das mulheres e o silenciamento do "ser mulher" em seus diversos aspectos. A pesquisa indica a necessidade de enfrentar desafios diversos no campo da docência no cárcere, destacandose, por exemplo, exclusões por gênero, classe, etnia, idade, entre outras. Defende-se uma educação (e uma docência) apoiada numa visão humanizadora, dialógica, crítica, capaz de promover processos de empoderamento das mulheres.

No artigo, A docência na Educação de Jovens e Adultos: limites e possibilidades da atuação docente, Laís Bastos Marchesoni, Viviane Gislaine Caetano Auada e Elsa Midori Shimazaki apresentam uma discussão de natureza conceitual, focalizando diferentes facetas de atuação docente no campo da alfabetização e escolarização de pessoas jovens, adultas e idosas em seus processos de apropriação crítica do conhecimento. As autoras refletem sobre a aprendizagem de conceitos científicos e, também, sobre a dimensão social do conhecimento, ancorados em conceitos como emancipação e participação social. Neste contexto, o pensamento de Paulo Freire aparece de forma destacada, evidenciando uma aproximação crítica na relação entre saberes escolares e saberes oriundos da vida dos sujeitos. A relevância do docente como sujeito capaz de contribuir com a construção do conhecimento em suas diferentes dimensões (científica, social, ética etc.) é permeada por um compromisso ético-político-social na configuração da docência, afirmam as autoras.

O artigo Docência na educação profissional: um olhar sobre o reconhecimento $e$ validação dos saberes experienciais, de Rodrigo Ademar Bender e Sita Mara Lopes Sant'Anna, busca compreender discursos de dois estudantes do ensino técnico profissionalizante sobre a

Periódico Horizontes - USF - Itatiba, SP - Brasil - e020058 


\section{HSE H O R I Z O T ES}

interface entre seus saberes experienciais e os saberes epistêmicos. Apresenta discussão oportuna, especialmente para o campo da educação de pessoas jovens, adultas e idosas, ao tratar da validação e do reconhecimento de saberes adquiridos no fluxo da vida dos sujeitos, possibilitando, também, reflexões relevantes para o campo do currículo escolar na relação educação, trabalho, vida, escola. No texto, os autores problematizam, criticamente, a perspectiva das competências, existente em propostas curriculares brasileiras. Defendem, ainda, que saberes experienciais sejam reconhecidos e validados, evitando, assim, apagar memórias e conhecimentos oriundos de outros processos de formação.

No artigo, Memórias de práticas docentes na EJA: redes outras de formação continuada de professores, de Francisco Canindé Silva, o autor apresenta uma pesquisa fundamentada, especialmente, em conceitos do pensamento complexo, de pesquisas no/do/com os cotidianos, assim como no sentido de memória. $\mathrm{O}$ trabalho com memórias docentes é situado como dispositivo teórico-metodológico capaz de contribuir, significativamente, com a formação continuada no âmbito desta modalidade, potencializando vozes docentes e evidenciando distintas experiências pedagógicas construídas no cotidiano de práticas pedagógicas vividas no campo de atuação profissional. Autoformação e rememoração são caminhos férteis, afirma o autor, no processo de formação continuada. Defende-se, no texto, a potencialidade de experiências docentes vividas no cotidiano escolar, muitas vezes aniquiladas e silenciadas pelas lógicas de imposição e prescrição de controles externos. Reconhecimento, potencialização, tradução e reconstrução de práticas pedagógicas cotidianas são movimentos, portanto, defendidos pelo autor no processo de formação docente, problematizando e atentando-se, assim, para lógicas imperialistas de produção do saber e ancorando-se na formação para a justiça social, para a justiciabilidade cognitiva, para processos emancipacionistas.

No artigo Reflexões sobre a prática docente: o desafio da qualidade no PROEJA, Helen Wanderley do Prado e Jupter Martins de Abreu Junior apresentam resultados de pesquisa sobre o PROEJA, situando e refletindo sobre aspectos de natureza histórica, política, social, curricular e de formação, no processo de elaboração e de materialização do Programa, 


\section{HSE H O R I Z O T ES}

explicitando tensões, desafios e potencialidades desta experiência desenvolvida no contexto brasileiro. Neste ínterim, são discutidos desafios cotidianos para se planejar e vivenciar práticas educativas numa dimensão emancipatória, considerando outras lógicas de formação docente para lidar com demandas de trabalhadores estudantes com suas experiências de vida distintas, trajetórias escolares interrompidas e saberes sociais e culturais diversos. O desafio da conclusão da educação básica de qualidade, entendida como direito constitucionalmente assegurado, é problematizado na relação direta com uma formação profissional capaz de assegurar, para as pessoas jovens, adultas e idosas, uma educação integrada, aliada a uma concepção humanística e emancipatória dos sujeitos.

O artigo intitulado Narrativas de vida de idosos na formação inicial de professores, cuja autoria é de Bethania Medeiros Geremias e Thayná Luana Borges, apresenta resultados de experiência envolvendo o ensino articulado à pesquisa, por meio de narrativas com duas pessoas idosas. O envelhecimento humano no campo da formação docente é problematizado com base em olhares diversos, indicando possibilidades de trabalho e estudo no campo das relações de gênero e da educação de pessoas idosas. Tomando como referência a história e as memórias de dois idosos, as autoras provocam um olhar sobre a necessidade de desconstruir diversos estereótipos sobre a velhice. O estudo contribui, ainda, com reflexões críticas acerca do tema desigualdade de gênero no âmbito da educação de pessoas jovens, adultas e idosas.

$\mathrm{O}$ artigo intitulado $O$ ensino da leitura na Educação de Jovens e Adultos: da vida para a escola, da escola para a vida, de Maria José Gomes Cavalcante e Eliana Borges Correia Albuquerque, buscou compreender as práticas de ensino da leitura e as relações possíveis entre estas e as práticas vivenciadas pelos educandos no contexto externo à escola. Refletese, no texto, sobre eventos de letramento propostos pela docente (participante da pesquisa) e sua relação com a prática social da leitura vivida pelos discentes. O texto evidencia uma prática docente efetiva, destacando diferentes estratégias de leitura e as experiências vivenciadas pelos educandos. Problematizam-se demandas de pesquisas em torno do ensino e da aprendizagem da leitura e da escrita em classes de EPJAI, campo que exige maior 


\section{HSE H O R I Z O T ES}

investimento, especialmente na relação entre alfabetização e letramento(s). A pesquisa explicita, ainda, avanços no trabalho com a leitura, especialmente na relação entre o contexto das práticas sociais dos estudantes e o acesso deles aos diferentes gêneros textuais do cotidiano.

Intitulado Levantamento de investigações sobre a Educação de Jovens e Adultos na Revista Boletim de Educação Matemática (Bolema), de Anildo Soares Flôr, Edvonete Souza de Alencar e Alessandra Cristina Furtado, o artigo apresenta resultados de um estado do conhecimento, realizado no período de 2009 a 2018, na Revista Bolema. Na pesquisa, foram identificados 22 trabalhos na interface Matemática e EPJAI. Destacam-se, no texto, as instituições, as metodologias de pesquisa, os autores de referência desta interface e as principais temáticas abordadas, traçando tendências investigativas deste campo no contexto brasileiro. Os resultados evidenciam a existência de colaborações institucionais e interinstitucionais para desenvolvimento de trabalhos no campo da Matemática em sua interface com a EPJAI, destacando-se propostas voltadas à oferta de recursos e experiências de ensino, bem como de formação docente para a área. A análise explicita, também, a necessidade de melhoria e aperfeiçoamento da relação entre o ensino da Matemática na EPJAI e os processos de aprendizagem dos educandos.

O artigo denominado Representatividade da população negra no material didático de Geografia do Programa "Nova EJA": para além da denúncia, um outro olhar, de Tiago Dionisio e Guilherme Pereira Stribel, apresenta a análise de um material didático de Geografia do Programa "Nova EJA", desenvolvido no Estado do Rio de Janeiro, problematizando a representatividade da população negra na fonte pesquisada. No texto, a Geografia é situada como campo de conhecimento que possibilita a constituição de leituras críticas do espaço social, colaborando, desse modo, com a análise da sociedade de forma a evidenciar contradições em torno de aspectos econômicos, sociais, raciais, históricos e culturais. Refletese sobre a necessidade de outra concepção educacional, capaz de potencializar e trabalhar a temática da representatividade negra nos materiais didáticos de Geografia utilizados em sala de aula. Defende-se, no artigo, uma formação voltada ao combate das desigualdades sociais 


\section{HSE H O R I Z O T ES}

e raciais, potencializando e vivenciando práticas antirracistas no cotidiano escolar, desconstruindo e denunciando, ao mesmo tempo, racismos institucionais, estruturais. Por fim, são questionadas desigualdades no campo educacional na EPJAI, chamando a atenção para a relevância de estudos sobre a história da África e dos povos africanos no contexto da educação brasileira.

A reflexão do conjunto de artigos desta segunda seção temática pode contribuir para diferentes (trans)formações e (re)existências no campo educacional, por meio da constituição de outras políticas públicas educacionais, de outras construções curriculares, bem como de novas dinâmicas de formação e práticas docentes, visando constituir processos de ensino e de aprendizagem numa perspectiva política, emancipatória, transformadora, autônoma, ética e estética.

Com a retirada, no ano de 2016, de forma autoritária, de Dilma Rousseff da Presidência da República Federativa do Brasil, o contexto educacional brasileiro passou a expressar, nestes últimos anos, a necessidade de fortalecimento de ações no campo das pesquisas na EPJAI, das políticas públicas educacionais, da gestão pública e escolar, do direito à educação, da formação docente, diante do silenciamento institucional em nível federal, expresso de forma intencional na ausência, por exemplo, de iniciativas governamentais e de Estado no tocante à EPJAI. Diante do exposto, há necessidade de mais resistências e integração de todos os movimentos sociais, universidades, institutos de formação, entre outros, visando assegurar políticas públicas e ações educacionais, sociais e culturais para atender, de forma qualificada, às demandas específicas desta modalidade.

Dezembro de 2020. 